\title{
Analysis of wave force on steel pipe pile under construction
}

\author{
Cheng Peng ${ }^{1, a}$, Longzai $\mathrm{Ge}^{1, \mathrm{~b}}$ and Bin $\mathrm{Yu}^{1, \mathrm{c}}$
}

${ }^{1}$ Key Laboratory of Engineering Sediment of Ministry Communications, Tianjin Research Institute for Water Transportation Engineering; No.2618, Xingang Erhao Road, Tianjin, 300456, China

apengcheng3127@163.com, bgelongzai@163.com, ‘416556570@qq.com

Keywords: Construction; Wave force; Steel pipe pile; Wave load; Physical model.

Abstract. In this research, a two-dimension physical model experiment was conducted, which studied the wave force characteristics on steel pipe pile under three different construction stages. The experiment results show that the single pile horizontal force maximum and sub-maximum and total horizontal force maximum are going down as the slope pavement construction, which indicates that the wave force on steel pipe pile appears in the early stage of construction. It is necessary to pay attention to protection work under extreme wave conditions.

\section{Introduction}

During the construction of port engineering, the hydraulic structure may be damaged by wave impact. Such as core rocks are exposed before placing armor blocks under construction of breakwater, the single caisson are installed before the whole caisson breakwater was built and so on. Therefore, it is necessary to study the safety of hydraulic structure during construction. Hydraulic structure's wave load plays an important role in engineering safety and cost. The existing research about wave force on piles is mainly from physical model, formula computing and numerical model aspects. Avinash M. Nafday [1] developed a probabilistic model of wave forces on cylindrical pile in 1983. Yiming Liu [2] studied the wave loads on pipe-group foundation in 2013. Yanbao Li [3] studied the breaker force on the vertical cylinder in the shallow water. This research is based on the steel pipe piles in front of vertical caisson, measured the wave force on steel pipe pile under construction stages, namely under different protection conditions. Analyze and compare the stress characteristics of steel pipe pile under different protection conditions.

\section{Equipment and Model arrangement}

The experiment is carried out in a wave flume. The wave flume is $68.0 \mathrm{~m}$ long, $1.0 \mathrm{~m}$ wide and $1.5 \mathrm{~m}$ high. At one end of the flume, the wave generator is set, the regular and irregular waves can be generated. Both ends of wave flume are equipped with the wave-absorption devices. The wave pressure is measured by point pressure sensor of Hydrodynamic Data Collection System named TK2008.

The caisson size is $25 \mathrm{~m} \times 15 \mathrm{~m} \times 17 \mathrm{~m}$, top elevation is $+2.0 \mathrm{~m}$. 7 rows and 7 columns of total 49 steel pipe piles are set evenly spaced in front of the caisson. The connection support of pile holder structures are on top of steel pipe piles. The three different construction stages are selected for experiment. Section 1 is a section without covered, after pile driving and the waves impact the caisson and steel pipe piles directly; section 2 is a semi-riprap protection, 3 6ton stones are laid to $-8.50 \mathrm{~m}$ elevation before the caisson; section 3 is standard design section, the 3 6ton stones are laid to $-6.0 \mathrm{~m}$ elevation and armor blocks are placed to cover the slope from $-6.0 \mathrm{~m}$ to $+1.0 \mathrm{~m}$ elevation. The steel pipe piles' layout and three states' cross section are shown in Fig. 1.

*Corresponding author.

E-mail address:gelongzai@163.com (Longzai Ge) 


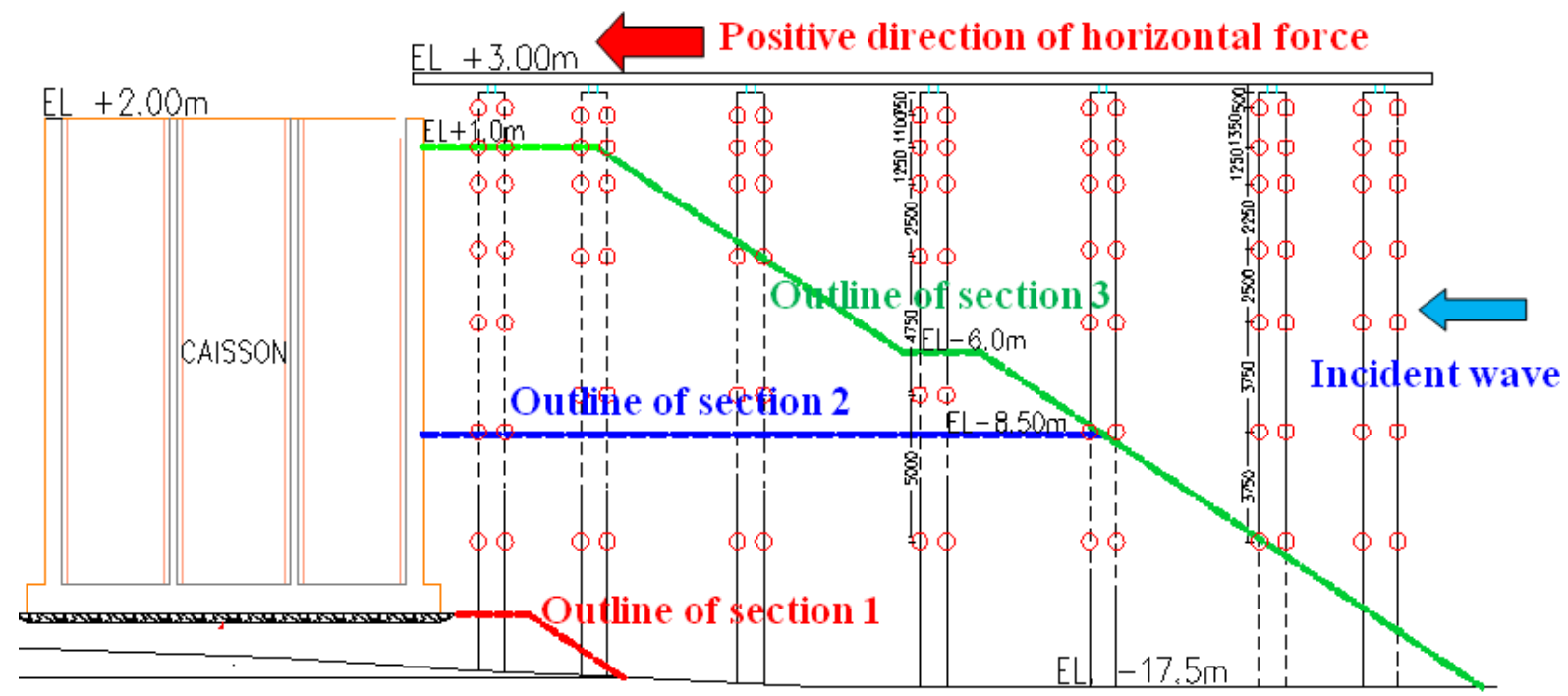

Fig. 1 Model arrangement and pressure sensor layout on steel pipe piles

\section{Wave condition}

The wave condition includes water level, wave height, wave period, wave type and spectrum is shown in Tab. 1. The physical model must satisfy gravitational similarity [4] and geometry similarity [5]. In this experiment, the geometry scale is 25 , that is mean the depth scale, wave weight scale, wave length scale all are 25 , the period scale is 5 , the force scale is 15625 .

Tab. 1 Wave condition of physical model

\begin{tabular}{ccccc}
\hline Water level $(\mathrm{m})$ & $\mathrm{H}_{\mathrm{s}}(\mathrm{m})$ & $\mathrm{T}_{\mathrm{s}}(\mathrm{s})$ & Wave type & Spectrum \\
\hline 1.0 & 5.75 & 12.20 & Irregular wave & Jonswap \\
\hline
\end{tabular}

\section{Analysis method of wave force}

In the experiment, the horizontal force positive direction is defined to parallel to the incident wave direction. For the normal experiment method of horizontal force on the pile, the measuring points are laid by every $45^{\circ}$ evenly on circular cross section. In this study, considering the pile diameter is small (steel pipe pile's diameter is $0.9 \mathrm{~m}$ ), so the measuring points are laid on the sea side and back side on the piles. For this kind of gauges arrangement method, the results are revised according to the calculation formula of pile foundation and pier column [6]. Then take the diameter of circular cross section's $45^{\circ}$ arc projection as a representative width and integrate along the pile length. A total of 92 pressure sensors are laid on the steel pipe piles, the sensor layout is shown in Fig. 1 in the previous paragraph.

\section{Experiment phenomenon}

In section 1, the wave impact the caisson after through the pile group, and overtopping happened on the top of caisson. In section 2, the wave climbed slightly along the underwater slope and then impacted the caisson. In section 3, because the elevation between caisson and armor layer are close, the wave climbed along the armor blocks and cross the caisson straight. The experiment phenomenons under different construction stage are shown in Fig. 2. 

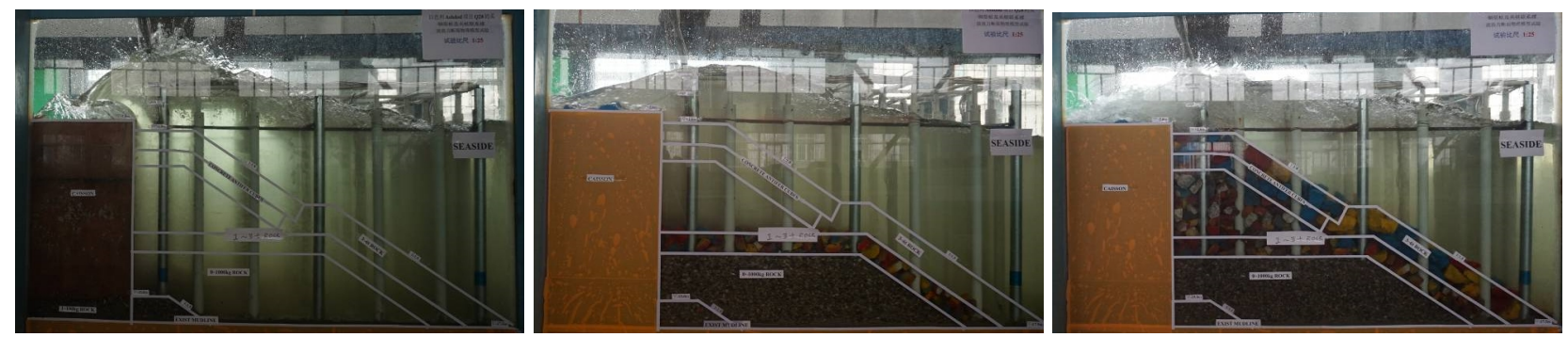

Fig.2 Experiment phenomenon under different construction stage

(From left to right are section 1, section 2 and section 3 )

\section{Results of maximum horizontal force of single pile}

The results of maximum horizontal force of single pile are shown in Fig. 3. The maximum and sub-maximum force value are $394.42 \mathrm{kN}$ and $391.52 \mathrm{kN}$ in section 1 ; the maximum and sub-maximum force value are $370.85 \mathrm{kN}$ and $320.86 \mathrm{kN}$ in section 2 ; the maximum and sub-maximum force value are $282.10 \mathrm{kN}$ and 311.40 in section 3 . The maximum of horizontal force appeared in the first row of piles in sea side, which hit by waves. The sub-maximum force of horizontal force appeared in front of the caisson since the reflection wave increased the wave force. And the maximum and sub-maximum force are going down as the slope pavement construction.

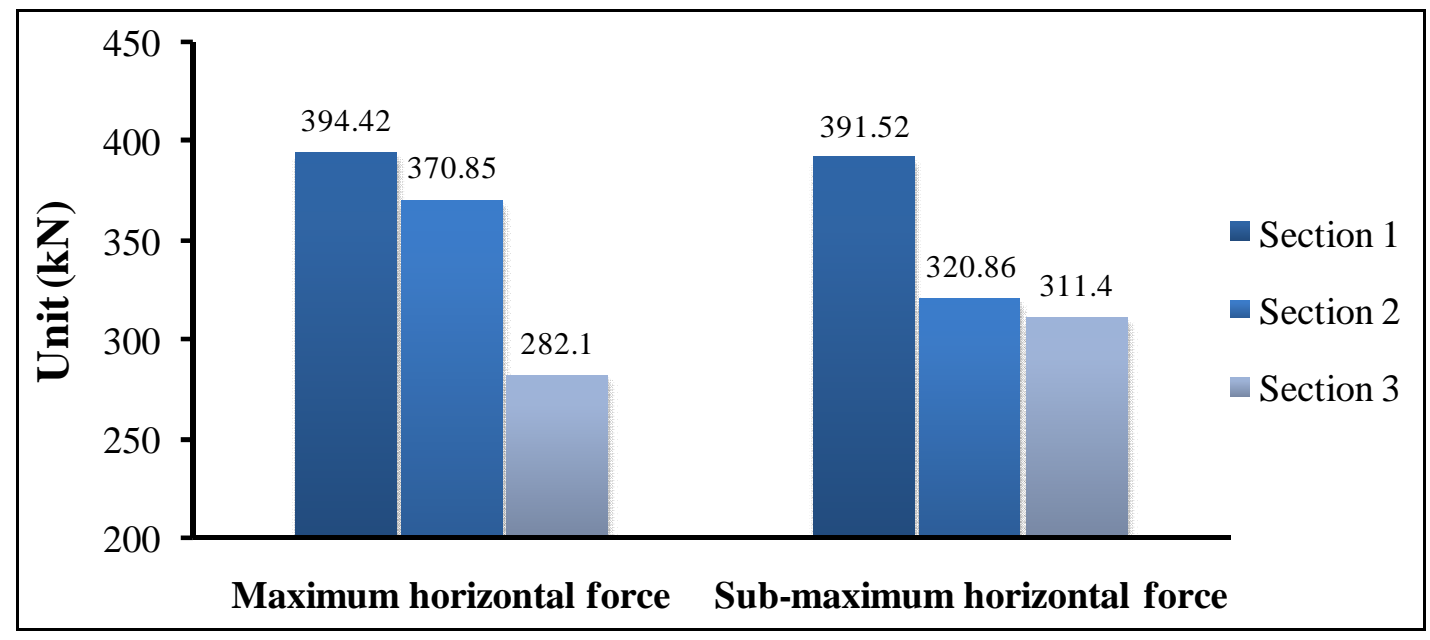

Fig. 3 Results of maximum horizontal force of single pile

\section{Results of maximum total horizontal force}

The results of maximum total horizontal force of 7 piles in the same column are shown in Fig. 4 . The total horizontal force could reflect the bearing condition of whole pile group. The maximum force value of each three section is $1481.40 \mathrm{kN}$ in section, $1403.87 \mathrm{kN}$ in section 2 and $1391.05 \mathrm{kN}$ in section 3. This due to the cover effect of stones and armor blocks to steel pipe piles is increase with the slop shape from no-riprap to semi-riprap then to the full coverage of armor blocks, which lead to the impact of waves decreased. 


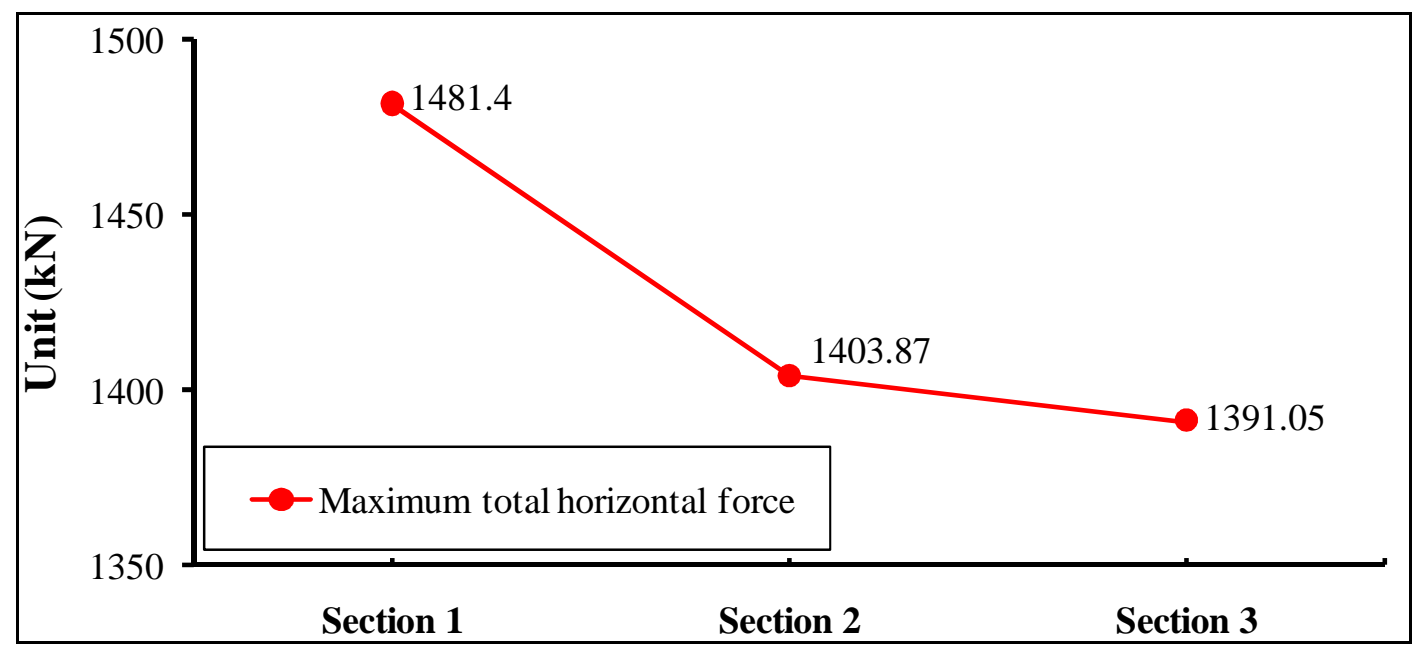

Fig. 4 Results of maximum total horizontal force

\section{Conclusions}

(1) The maximum of horizontal force is $394.42 \mathrm{kN}$ appears in the first row of piles in sea side in section 1; the sub-maximum of horizontal force is $391.52 \mathrm{kN}$ appears appeared in front of the caisson in section 1. And the maximum and sub-maximum force are going down as the slope pavement construction. (2) The maximum of total horizontal force of 7 piles in the same column is $1481.40 \mathrm{kN}$ in section 1. The relationship of total horizontal force in three sections is section 1 is greater than section 2 and greater than section 3. (3)The results indicate that the wave force on steel pipe pile appears in the early stage of construction. It is necessary to pay attention to protection work under extreme wave conditions.

\section{Acknowledgements}

The authors gratefully acknowledge the financial support provided by Central Commonweal Research Institute Basic R\&D Special Foundation of TIWTE (Grant No. TKS160107); Applied Basic Research Project funded by Ministry of Transport, China (Grant No.2014329224380); National Natural Science Foundation of China (Grant No. 51409135) and Tianjin Applied Basic and Frontier Technology Research Project (Grant No. 15JCQNJC07300).

\section{References}

[1] Avinash M. Nafday, Hsiang Wang. Probabilistic Model of Wave Forces on Cylindrical Pile[J]. Journal of Waterway, Port, Coastal, and Ocean Engineering. 1983(2)

[2] Yinmin Liu. Analysis of Wave Loads on Pipe-Group Foundation[D], Shanghai University, 2013

[3] Yanbao Li. Experiment Research of the Breaker Force on the Vertical Cylinder in the shallow water[J]. Sea \& Lake, 1992, 23 (6): 635-640

[4] BS 6349: British Standard Code of Practice for Maritime Structure, British Standards Institution.

[5] Users Guide to Physical Modelling and Experimentation. L.E Frostick, S.J. Mclell and T.G. Mercer. Published by CRC Pres. ISBN 978-0-415-60912-8.

[6] Code of Hydrology for Sea Harbor JTS 145-2-2015 issued by the Ministry of Communications of the People's Republic of China. 